\title{
Evaluating dimensional stability in solid wood: a review of current practice
}

\author{
R. Sargent ${ }^{*}$ (1)
}

\begin{abstract}
The degree with which wood shrinks and swells with changing moisture content is an important property which determines its suitability for different applications. This property, known as dimensional stability, is often a target property for improvement in wood modification research. Its importance makes it a commonly quantified wood property. Despite this, methods for measuring dimensional stability are not standardised, and there is little consensus on appropriate test methods. Dimensional stability tests can be classified according to the method used to change the moisture content of the wood (liquid water or water vapour) and the duration of the test (until equilibrium is reached, or a shorter duration). Each class of test represents a situation that wood products may encounter in service, and different types of wood (modified or otherwise) may respond differently to each situation. This means that comparative performance between different wood types may be dependent on the test used (and may not be valid for some situations encountered in service). In this paper, standard test methods and methods described in the literature are compared, and recommendations are given for selecting an appropriate dimensional stability test and for minimising sources of bias and measurement uncertainty in the test. It is expected that this will also encourage the adoption of more standardised test methods, enabling comparisons to be made between different studies and different wood types.
\end{abstract}

Keywords: Dimensional stability, Moisture, Modified wood, Swelling, Test methods, Wood

\section{Introduction}

Dimensional stability affects how a final wood product will move and distort in service and consequently is an important wood property to understand. This is particularly true in wood modification research and among processers of modified wood products, where the modification processes often aim to improve dimensional stability. Despite this, the concept of dimensional stability is not always well defined, and there are numerous methods used to measure dimensional stability, with little consensus on test methods or metrics used. In this paper, 'stability' refers to dimensional stability-the amount a piece of wood shrinks or swells in response to a change in its moisture content, or a change in moisture in its environment. Shape stability (the change in the overall shape of boards with changes in moisture content) is related, but is beyond the scope of this work. Wood dimensions and

*Correspondence: rosie.sargent@scionresearch.com

Wood and Fibre Science, Scion, 49 Sala Street, Rotorua, New Zealand levels of distortion can also change via further processing of wood that already has internal stresses, or through cell collapse during drying. These shape changes due to internal stresses are also not included in the present definition of stability, even though they are sometimes referred to as 'instability' or 'shrinkage'.

Currently, a wide variety of tests, based on two basic underlying principles (contact with liquid water and contact with water vapour), are used to measure stability. Some methods are very popular, such as determining Anti-Shrink Efficiency (ASE) from the water-soak ovendrying test, but there is no one method consistently used; hence, details of methods can vary considerably between facilities. Many method variations will still yield similar results, but some methods compromise the properties being measured, potentially giving misleading results.

When measuring dimensional stability, ideally, the properties measured will give an indication of how wood will behave in service and will also enable comparisons between different wood types (e.g., species) as well as 
comparisons between samples tested at different times and at different facilities. Tests also need to be repeatable and standardised, so that results from different laboratories or from the previous measurements can be compared in a meaningful way.

This paper outlines commonly used test methods for evaluating dimensional stability, including method development to date, e.g., Van Acker [1]; Sargent et al. [2], and from this gives recommendations on how best to choose (or develop) an appropriate test method for determining dimensional stability. In the following sections, test methods described in standards and used in the literature are compared. Their suitability for predicting in-service dimensional stability and any potential sources of uncertainty in particular test methods are discussed. The test methods are divided into those that use liquid water and those that use water vapour, and further subdivided into tests that allow enough time for samples to become equilibrated with their surroundings or tests that measure transient behaviour over shorter time periods.

\section{Dimensional stability tests involving liquid water}

These tests involve contacting the wood with liquid water (usually by soaking the wood in water). Broadly speaking, water-soaking tests can be grouped into two classes; water-saturation tests, where the wood is soaked until it is fully saturated (usually over $24 \mathrm{~h}$, often with the addition of vacuum or pressure step) [3]; and 'swellometer' tests, where wood is soaked in water for a short-time period (typically $30 \mathrm{~min}$ ), and the change in a single dimension is measured [4]. Tests involving liquid water are particularly suited to wood used in applications where regular contact with water is expected (e.g., outdoors), but even for indoor applications, where water contact is not expected, wood may still occasionally be in contact with water (e.g., leaks, spills) and it may be useful to understand how the wood will behave under these extreme conditions.

\section{Water-saturation tests}

Water-saturation tests are commonly used in wood modification research, especially in Europe. The most common water-saturation test is the repeated water-soak test, used to calculate ASE. In this test, wood volume changes are compared between complete water saturation and oven dryness and this volume change is compared to that of an unmodified reference sample (of the same wood species) to calculate ASE [5]. This popular test is relatively quick to perform, does not require specialist facilities (such as climate controlled cabinets), and gives a direct comparison with the behaviour of an unmodified reference sample, making it particularly suitable for the development of modified wood products (but not suitable for comparing different wood species, due to the lack of a standard reference between different tests). While repeated water soak (to calculate ASE) is a widespread test, it does have some shortcomings; it is by nature a very harsh test, so does not correspond well to behaviour in service conditions, especially for indoor applications [3]. However, in some outdoor applications, the wood will be in contact with liquid water, so a test involving some kind of water soaking will be appropriate (even though these in-service conditions will not be as harsh as oven drying, or pressure saturation of wood). Noack et al. [6] note that neither oven dry nor fully saturated conditions will ever be seen in service. Because swelling behaviour is non-linear between these two conditions, comparing them has limited predictive value for in-service performance, even in applications, where contact with water will occur.

\section{Commonly used test methods}

Hill [3] noted the lack of standardised tests for evaluating stability in modified wood and described international adoption of agreed protocols as "a matter of great urgency". Despite this, there still appears to be no accepted standard method for the repeated water-soak test, and while many tests appear similar, there are many subtle variations in test methods. Specimen sizes can vary from short cross sections cut from an entire board (e.g., $15 \mathrm{~mm}$ cut from an $18 \times 40 \mathrm{~mm}$ board in Bak and Németh [7]) to small $(20 \times 20 \times 5 \mathrm{~mm})$ biscuits [8]. Sometimes, one soaking cycle is used [9], or as many as 10 soaking cycles [10]. Samples can be soaked for a set length of time [11], or soaked until they reach constant dimensions [12]. While results are generally reported as ASE values, sometimes, the percentage swelling (S) of individual samples is reported [13, 14]. Ohmae et al. [15] calculated the anisotropy ratio (tangential dimension change divided by radial dimension change) for different modifications and found that cell-wall modifications decreased anisotropy, whereas lumen filling modifications increased it. As an alternate measure of anisotropy, García Esteban et al. [16] correlated tangential dimension change vs. radial dimension change. Changes in anisotropy are likely to affect in-service behaviour of wood, specifically shape stability and the development of surface and internal checking, but further work would be needed to see how changes in anisotropy (e.g., via wood modification) affected in-service performance. Anisotropy can be calculated from data collected in most dimensional stability experiments, but it is not often quantified.

As well as making it difficult to compare results between studies, some variations in test methods can have an effect on the accuracy of the results measured. There has been some work on improving methods for the repeated water-soak test, such as that by Van Acker 
[1], who began a systematic look at factors that will affect the accuracy of repeated water-soak tests. However, other method improvements have been more piecemeal and are generally not specifically reported as method improvements, such as the discussion on the effect of cycle number on ASE in Hill and Jones [10], or the use of brass domes embedded in samples to improve measurement accuracy in Fredriksson et al. [14].

\section{Methods for resaturating wood}

Different methods of resaturating wood can affect how much it swells. For example, Almeida and Hernández [17] and Naderi and Hernández [18] found that resaturating dried blocks of beech (Fagus grandifolia Ehrh.) or sugar maple (Acer saccharum Marsh.) by immediately placing dried blocks in water produced more swelling than for a less severe method, where samples were equilibrated to high moisture contents before resaturation. While the effect of the customary (and even more severe) method of vacuum (and sometimes pressure) impregnation on swelling is not known, it is potentially not a good predictor of liquid water absorption in-service. Van Acker [1] found that up to six vacuum soaking cycles are required to attain constant dimensions, but did not note any differences between modified and unmodified samples. Wood modifications that improve stability will, by necessity, alter the way the wood interacts with water, so they are likely to affect resaturation behaviour. Sargent et al. [2] found that modified wood samples continued to increase in dimension for up to $48 \mathrm{~h}$ when soaking in water after vacuum-pressure resaturation. It is common to soak samples for $24 \mathrm{~h}$ following resaturation, so it is likely that measurements are made on samples that have not attained their final dimensions. It is not known if the water-soaking and oven-drying methods used for unmodified wood are directly applicable to modified wood, or if longer soaking/drying times are required to give results comparable to that of unmodified wood.

\section{Effect of number of cycles and oven-drying method}

Several studies suggest that the first cycle of the repeated water-soak test is often not representative of subsequent cycles. For chemical modifications, leaching of any nonbonded chemicals will make the ASE from the first cycle higher than in subsequent cycles $[19,20]$. Hill and Jones [10] found that this effect of cycle still held for samples that had been Soxlet extracted prior to testing, including for the unmodified controls, suggesting that the extraction process itself was also affecting the behaviour in the first water-soak/oven-dry cycle. For these reasons, multiple cycles are often used and the results from the first cycle are discarded $[8,14]$. Therefore, a method that can withstand multiple water-saturation cycles is necessary for representative results. Hill and Jones [10] noted that while they measured ASE for 10 cycles, most of the unmodified samples did not survive the full ten cycles and developed serious cracks after as few as five cycles. In preparing this review, no direct evidence of cracking affecting ASE measurements was found, either in the literature, or from experimental data. Cracking would be expected to reduce the level of shrinkage on oven drying by reducing the drying stress in the sample. Chafe [21] found conflicting results comparing shrinkage with levels of internal checking in Eucalyptus regnans F Muell.some drying treatments showed decreased shrinkage with increased internal checking, but some drying treatments showed no significant relationship. This is an area which could possibly benefit from further research. Hill et al. [8] used a two-stage drying method-drying at $60{ }^{\circ} \mathrm{C}$ for $24 \mathrm{~h}$, followed by $105^{\circ} \mathrm{C}$ to constant weight. The reason for this two-stage drying is not mentioned, but it is assumed that it is to minimise damage to the samples. Čermák et al. [20] used a three-stage drying process, starting at $40{ }^{\circ} \mathrm{C}$ and ending at $103{ }^{\circ} \mathrm{C}$ to prevent specimens from cracking. DIN 52184 [22] specifies a threestage oven-drying method, with $24 \mathrm{~h}$ each at 50 and 80 before drying at $103{ }^{\circ} \mathrm{C}$ to constant weight. Recently, an initial kiln-drying step with humidity control $\left(50{ }^{\circ} \mathrm{C}\right.$ dry bulb, $40{ }^{\circ} \mathrm{C}$ wet bulb) was shown to reduce the checking caused by oven drying [2].

\section{Effect of sample preparation and measurement technique}

Because the dimensional stability of wood varies greatly with grain direction, in service, it is common that changes in dimension in one particular grain direction is going to be of primary concern and a volumetric stability measurement is not necessarily going to give a good indication of performance. Hill [3] stresses the importance of having samples free of defects and with growth rings exactly parallel to one edge of the sample. This is backed up by Van Acker [1] who found that ASE measurements varied substantially with variations in grain directionsamples with growth rings deviating by up to $30^{\circ}$ from parallel showed a reduction in ASE from 70 to $53 \%$.

Specimen dimensions are typically measured with calipers, sometimes in several places around the cross section of the specimen. Alternatively, for water-saturated samples, the specimen volume can be calculated by water displacement, as is often done when determining basic density [23]. Sargent et al. [2] found that volumes determined by water displacement are equivalent to those calculated from individual measurements taken with calipers and that measuring volume by displacement leads to fewer outliers in the data, suggesting a reduction in measurement errors. Oven-dry volume can also be determined by water displacement, but the specimens must be 
dipped in paraffin first [23]. This method is particularly useful for specimens, where it is difficult to measure the dimensions accurately (such as those that have developed severe cupping). The use of paraffin is only feasible after the final oven-drying step; otherwise, it would interfere with subsequent testing. Where there are no problems measuring specimen dimensions with calipers, determining oven-dry volume by measuring individual specimen dimensions is recommended.

Water-saturation tests are widespread in wood modification research and for good reason. Tests are quick to perform, and require minimal specialist equipment. For the repeated water-soak test, the test results quantify the improvements in dimensional stability from a given modification, so is useful in development work. It is important that the correct test method and correct measurement equipment is chosen, as these will have an effect on the accuracy of the results. Adoption of standard test methods between organisations would allow better comparisons of results between different studies.

\section{Short-term water-soaking tests}

For evaluating short-term dimensional change with water, "Swellometer" tests are a popular method for evaluating Anti-swell efficiency (denoted here as $\mathrm{ASE}_{\mathrm{w}}$ to avoid confusion) of both modified wood and water-repellent surface treatments in North America [24, 25]. This test involves equilibrating thin wood samples (usually $6.4 \times 25.4 \times 127 \mathrm{~mm}, \mathrm{~L} \times \mathrm{R} \times \mathrm{T}$ ) at $65 \%$ relative humidity $(\mathrm{RH})$ and then soaking samples in water for a short time (usually $30 \mathrm{~min}$ ) and measuring the change in the tangential direction [26]. Another commonly used test methodology is from the United States-based Window and Door Manufacturers Association [4]. This method is almost identical to the ASTM standard, but uses a slightly narrower sample in the radial direction $(25 \mathrm{~mm}$ vs. $38 \mathrm{~mm}$ ) and prior to testing, and equilibrates the samples at a higher temperature and RH than the ASTM test $\left(27{ }^{\circ} \mathrm{C} / 65 \%\right.$ RH vs. $\left.23{ }^{\circ} \mathrm{C} / 50 \% \mathrm{RH}\right)$. These differences would not be expected to have a material effect on the test results. Results can either be reported as $\mathrm{ASE}_{\mathrm{w}}$, or as water-repellent efficiency (WRE) or water-repellent percentage value (WRV) [24]. Confusingly, WRE can also be used to compare the change in weight between the treated samples and controls [27]. One other potential shortcoming of the standard Swellometer test is that it only measures stability in one-grain direction.

When wood comes in contact with liquid water, it is often for a limited period of time, e.g., a period of rain, or a spill on a wooden floor. This means that understanding how wood responds to water over short-time periods is important, and is more relevant to in-service behaviour than the final wood dimensions following pressure resaturation. The standard swellometer test and the metrics calculated from it were developed for one particular application (to measure the effect of water-repellent coatings compared to uncoated wood), which means that it would not be suitable for comparing different wood species. Different wood species and different wood modifications are likely to vary both in the total amount, they swell in water, but also the rate at which they swell. The current test only measures a single value-the amount of swelling that has occurred after $30 \mathrm{~min}$. When comparing different types of wood, where both the rate of swelling and the total amount of the swelling differ, the swelling after 30 min will not give a complete picture: a wood type that swells very little, but does so quickly could look identical to a wood type that swells a lot, but does so very slowly. Because contact with water over short-time periods is a common occurrence in many applications, it would be good to see a test method developed that could quantify both the rate and the total amount of the wood swelling in water and to report this in a way that is suitable for both modified wood, and for comparing the behaviour of different wood species.

Tests involving contact with liquid water are reasonably quick to perform, and do not require a lot of specialist equipment. In many applications, wood is likely to come in contact with liquid water, either on a regular basis (e.g., outdoors) or under exceptional circumstances (e.g., a leak indoors). Understanding how wood responds to contact with water, either over long- or short-time periods are important. Ideally, these results would be standardised and could be compared with other wood species, or other competing building materials. In most applications, wood will be exposed to changes in air humidity more often than it will be in contact with water, so understanding how wood behaves with changes in air humidity should not be neglected.

\section{Test methods involving exposure to humid air}

There are two main types of humidity exposure tests: equilibrium tests, where samples are allowed to come to weight equilibrium at each humidity condition, and short-term tests, where samples are placed in a humid environment for a set period of time (not long enough to come to equilibrium) before being measured. Tests can either involve single changes in relative humidity for each specimen (step-change tests) or each specimen can be cycled between different humidity levels a number of times (cycling tests).

\section{Shrinkage from green to $12 \%$ moisture content}

One extreme variant of the step-change test is measuring the dimensional change that occurs during initial drying. The results are generally either reported as the dimension 
change from green to $12 \%$ moisture content (MC) or from green to oven dry. This is very commonly used in industry to compare the dimensional stability of different wood species [27]. While this will give a broad indication of the relative levels of dimensional stability for two wood species, Noack et al. [6] suggest that dimensional changes relative to green dimensions are not relevant for in-service conditions, because after initially drying from green, even prolonged soaking in water will not reach full water saturation again, meaning that this condition is rarely seen in practice. In addition, shrinkage behaviour above the fibre saturation point (FSP) is highly non-linear, so predicting levels of shrinkage in partially resaturated wood are difficult. Instead, swelling based on different relative humidity conditions is suggested as a better way to predict the relative in-service performance of different wood types. The majority of wood modifications are performed after wood has been dried. For these, the concept of the 'green' dimensions of the modified sample does not have a lot of meaning, because the modification alters the state of the wood during processing, so the final, modified wood matrix has never existed in a green state.

\section{Equilibrium humidity-cycling tests}

Equilibrium humidity tests are by far the most popular type of humidity exposure tests. While there are standards describing step-change equilibrium humidity tests $[22,28]$, there does not appear to be an accepted standard method for humidity-cycling tests. However, all tests tend to follow a similar form:

- Wood samples are left in a constant humidity environment until the mass has equilibrated,

- The dimensions are measured,

- The samples are then equilibrated at a second humidity and dimensions measured again.

This is repeated to cover a range of humidity conditions, often cycling between high and low humidity levels a number of times. The samples are usually oven dried at some point during the testing (either at the beginning or end of the cycling). Results are reported either as a dimensional change from oven-dry $[29,30]$, or less commonly as a volumetric ASE [31,32] compared to the volume change of unmodified control samples (making this method only suitable for modified wood, not for comparing different wood species). DIN 52 184 [22] only specifies methods for water-saturation or humidity stepchange tests (between 35 and $85 \% \mathrm{RH}$ at $20{ }^{\circ} \mathrm{C}$ ), but it gives a number of formulae for interpreting the changes in dimensions either from an oven dry or water-saturated state. One is the swelling coefficient, which is defined as the percentage change in dimension (either radial or tangential) for every $1 \%$ change in relative humidity. This is a simple metric that is easy to understand, and makes for easy comparisons between the behaviours different types of wood. This method can easily be adapted to humidity-cycling tests by fitting a line through the dimensional change at each relative humidity level [2]. Awoyemi [33] compared dimensions of samples at 30 and $12 \% \mathrm{MC}$ and found that increasing levels of microwave modification decreased the anisotropy ratio (tangential dimension change divided by radial dimension change) in Eucalyptus obliqua L'Her. Changes in anisotropy are likely to affect in-service behaviour of wood and can be calculated from data collected in most dimensional stability experiments, but they are not often quantified. It would be of value for more experiments on the effect of anisotropy on in-service behaviour of wood (e.g., differences in levels of distortion or cracking) to be reported.

\section{Equilibrium moisture content as a predictor of dimensional stability}

The sample masses measured during humidity-cycling tests can also be used to calculate equilibrium moisture content (EMC) at each humidity condition. EMC reduction (comparing the EMC of modified wood to that of an unmodified control) is sometimes used to estimate improvements in dimensional stability. Sik et al. [34] used the reduction in EMC between high temperature dried rubber wood (Hevea brasiliensis Müll.Arg.) and control samples to predict improvements in dimensional stability. Rautkari and Hill [35] compared EMC change, mass loss and ASE for thermally modified Scots pine (Pinus sylvestris L.) and did not always find a good correlation between them, suggesting that EMC change is not a good substitute for directly measuring dimensional stability.

\section{Effect of oven drying and number of humidity cycles}

At some stage during testing, samples need to be oven dried to obtain oven-dry dimensions and masses. The oven-drying step (generally $103-105{ }^{\circ} \mathrm{C}$ with no humidity control) irreversibly reduces the hygroscopicity of wood [36]. In the pulp and paper industry, this process is called hornification and the structural basis for the changes is described in Weise and Paulapuro [37]; Östlund et al. [38] and Pönni et al. [39]. Because of this change in hygroscopicity, oven drying prior to humidity cycling will compromise the results obtained, so it is important that samples are not oven dried until after all humidity-cycling tests are complete.

As with water-soaking tests, the behaviour in the first humidity cycle appears to be different to behaviour in subsequent cycles [40]. Many tests use multiple $\mathrm{RH}$ cycles $[16,41,42]$, but some only used a single cycle [30, 43]. García Esteban et al. [16] found that water uptake 
decreased with subsequent humidity cycles, this was confirmed in their discussions with woodworkers who had observed that wood became more stable (and thus easier to work with) as it aged. In their study, care was taken to use desiccant to 'oven-dry' the samples at room temperature, to avoid the irreversible change in sorption behaviour caused by oven drying (as shown in Hoffmeyer et al. [36]). After four RH cycles, the wood dimensions had stabilised and behaved identically in subsequent cycles.

\section{Effect of drying history on sorption behaviour}

Drying history can also have an effect on the sorption behaviour. Ishimaru et al. [44] compared dimensions of samples that had been dried after equilibrating to a high humidity with samples dried from full water saturation. The samples dried from saturation showed greater dimensional changes compared to the humidity conditioned sample and this was attributed to water tension within the wood causing shrinkage stress and subsequent irreversible deformation. This phenomenon was also noted by Rafidah et al. [45] when comparing ovendry dimensions after solvent extraction with those after water-saturation tests. Some stability tests use a combination of water soaking and humidity cycling. This provides a potential source of error if results from samples with a water saturation/oven-dry history are compared to samples with no such history. Despite this, some test methods require specimens to be water saturated immediately prior to humidity conditioning $[13,28]$. The effect of sorption hysteresis [5] will impact the moisture contents in the first humidity cycle if samples are at very different moisture contents prior to humidity cycling. Hysteresis effects will also be an issue in humidity tests, where only a single-step change in humidity is measured, such as in European Standard BS/EN 318 [46], where dimension changes of wood-based panels are measured in a step from 65 to $30 \% \mathrm{RH}$ and a matched set of samples are measured from 65 to $85 \% \mathrm{RH}$-the results obtained will not necessarily be a good prediction of dimensional stability for humidity steps in the opposite directions. The New Zealand Standard AS/NZS 4266.14 [47] has a nearidentical step-change test. Interestingly, Ishimaru et al. [44] suggested that sorption hysteresis may be a transitional phenomenon which disappears over very longtime scales. They equilibrated wood samples for 50 weeks and were still seeing changes in moisture content after this period (over the final 100 day samples changed EMC by up to 1 percentage point).

\section{Test conditions and determination of equilibrium}

Monitoring weights to ensure that samples have reached a constant weight is almost universal in these tests. Barkas [48] notes that sorption behaviour is very time dependent and it can take months for samples to reach equilibrium. He cites a study of leather, where plastic flow within the sample was still occurring over several months, suggesting that sample dimensions may take longer to equilibrate than sample mass. In practice, equilibrium is usually said to be reached when weight changes are equivalent to the experimental error (e.g., weight change below $0.1 \%$ over $24 \mathrm{~h}$, as specified in DIN 52184 [22]).

Sample dimensions vary between test methods, varying from thin 'biscuits' cut from a full-size board [42], to small $23-30 \mathrm{~mm}$ cubes [30, 43]. ISO 4469 [28] gives dimensions of $20 \mathrm{~mm}$ in the transverse directions and $10-30 \mathrm{~mm}$ in the longitudinal direction. Increased longitudinal dimensions will increase the time taken for samples to reach equilibrium. Increases in transverse dimensions do not have this effect and larger dimensions are likely to reduce measurement errors, leading to more accurate results without increasing the time required to reach equilibrium.

Conditions used in humidity-cycling tests vary widely. Standard temperature conditions are $20^{\circ} \mathrm{C}[22,28]$, but other temperatures are used, some as high as 27 or $30{ }^{\circ} \mathrm{C}$ [41, 43], or different temperatures can be used for each RH condition [42]. Relative humidity conditions used in studies vary considerably in both the number of humidity conditions used and the humidity conditions themselves. Ishimaru et al. [44] used 15 different conditions; some studies only use two conditions [31, 43].

Changes in atmospheric humidity are the most common cause of wood moisture changes in service, and these often occur over long-time periods, so it is important to understand how wood will behave under these conditions. As with the water-soaking tests, there is little standardisation of test methods between different studies. Adoption of standardised test methods would ensure results were not compromised by inappropriate test conditions (e.g., oven-drying samples prior to testing), and allow easier comparisons between different studies and between different wood species (including comparisons with modified wood of a different species). There are drawbacks to the equilibrium humidity-cycling test; tests often take months to complete and results are only relevant to situations, where humidity is relatively stable over long periods of time, allowing samples to come to equilibrium.

\section{Short-term humidity tests}

The longer it takes a piece of wood to reach equilibrium, the less likely it is to actually reach equilibrium in service. Pfriem et al. [49] found that thermally modified Norway spruce (Picea abies (L.) Karst.) took longer to reach EMC than unmodified wood, but experiments by Bak and Németh [7] found that thermally modified poplar 
(Populus $\times$ euramericana cv. pannónia) took the same amount of time to reach equilibrium compared to control samples. It is not known how other modifications affect the time taken to reach equilibrium. In service, wood will often be exposed to large changes in humidity over shorttime periods, e.g., changes in weather over a period of a few days, and this short-term humidity response will not necessarily correspond to that of the equilibrium conditions. For these reasons, understanding the short-term response of wood to humidity changes is important for predicting in-service behaviour, but there appear to be very few tests that measure this. Harris [50] noted large differences in the time taken for different wood species to attain equilibrium (from days to months), so developed a test to measure the rate at which wood swells when exposed to a high humidity environment. In this test, samples are equilibrated at $65 \% \mathrm{RH}$, then placed in a high humidity environment for $24 \mathrm{~h}$ and the change in dimensions measured. These results were compared to the swelling from equilibrium at $65 \%$ relative humidity to full water saturation (following 1 week of soaking in water). Using the volume of resaturated wood, rather than green wood, it was intended to avoid the irreversible shrinkage encountered during initial drying from green to $12 \%$ EMC. For some species, quite different results were obtained between the two tests. Species with similar levels of swelling when soaked in water could have quite different levels of swelling after $24 \mathrm{~h}$ at high humidity. For example, both rewarewa (Knightia excelsa R.Br.) and southern rata (Metrosideros umbellata Cav.) swell by around $10 \%$ when soaked in water, but after $24 \mathrm{~h}$ at high humidity, rata only swells half as much as rewarewa $(1.7 \%$ compared to $3.4 \%)$. In the short-term tests, redwood (Sequoia sempervirens D.Don) swelled a similar amount to southern rata $(1.5 \%)$, but when soaked in water only swelled a quarter as much as the rata (2.5\%).

Haslett [51] also gives stability data for both longand short-term moisture cycling tests for a variety of New Zealand grown timbers. In general species with a large dimensional change, over long-time periods also had larger changes over short periods, but there is a lot of variation, and two species with the same long-term dimensional change could have quite different short-term dimensional changes, e.g., Pinus radiata D.Don changing dimension by $2.2 \%$ over $24 \mathrm{~h}$ compared to Eucalyptus botryoides $\mathrm{Sm}$. changing dimension by $1.5 \%$ over the same period. These two studies show that between different wood species, there are large variations in both the total amounts that they shrink or swell with changes in moisture content and the rate at which they shrink or swell. These differences are likely to affect the in-service performance of these timbers, or the compatibility of using two timbers together, so are important to understand.
In nearly all end uses for wood, changes in air humidity will be a major source of moisture content changes, and hence dimensional instability. For this reason, it is important to conduct both humidity-cycling tests and watersaturation tests to get a full understanding of the wood behaviour. Compared to the repeated water-soak test, humidity-cycling tests are more appropriate for characterising the behaviour of different wood species or for wood modifications that are close to market, to give performance comparisons between the modified wood product and other competing products. Limited data are available for short-term humidity tests, but these appear to measure differences in wood behaviour that equilibrium humiditycycling tests do not, so should be investigated further.

\section{Recommendations for test methods}

Based on this review of published test methods, the following recommendations are given to minimise experimental errors and to ensure that test results are representative of actual wood behaviour.

\section{Water-saturation tests}

Water-saturation tests are fast to perform, and do not require much specialist equipment. They give comparative results which are useful for quantifying improvements in dimensional stability gained from wood modifications or surface treatments, but are less useful for comparing different wood species. This means that water-saturation tests are very useful as a screening test as new treatments are being investigated. In addition, they will give useful information about how wood will perform in situations where liquid water may be in contact with the wood for long periods (1 or more days).

To give good results in repeated water-saturation tests, and minimise experimental errors, the following are recommended (in approximate order of importance):

- Prepare specimens with the largest practicable radial and tangential dimensions. These are the principle directions, where shrinkage occurs, and larger specimens will reduce measurement errors, and ensure that dimensional changes are larger than the measurement uncertainty of the instrument used, even for very dimensionally stable material.

- Ensure growth rings are aligned correctly with sample edges. Shrinkage is different in the radial and tangential directions, and misalignment between the growth rings and the measured direction will mean that the measured radial and tangential shrinkage will be different to the actual radial and tangential shrinkage.

- Ensure specimen dimensions are consistent. Because shrinkage rates vary so much with grain 
direction, specimens with different dimensions will have different volumetric swelling rates.

- Use the most accurate and repeatable measurement tool available to minimise measurement uncertainty-a bench-mounted gauge is much better than hand-held calipers. Computer-interfaced instruments reduce the risk of transcription errors, compared to recording values by hand.

- For water-saturated samples, measuring the specimen volume by water displacement is faster and more accurate than measuring the individual specimen dimensions. For excessively cupped specimens, the oven-dried volume can be determined at the completion of testing by water displacement after sealing the wood surface (e.g., dipping the specimen in paraffin).

- Mark dimensional measurement points with physical reference marks or tabs. This ensures that dimensions are consistently measured at the same point giving greater accuracy and repeatability.

- Pay attention to surface preparation-a smooth surface is required for accurate and repeatable dimension measurements. Smooth surfaces are also less likely to trap bubbles during water displacement measurements, reducing the chance of measurement errors.

- Ensure specimens come to equilibrium during water saturation-at least $48 \mathrm{~h}$ is required, but a much longer time may be necessary. For novel wood modifications designed to increase dimensional stability, the soaking time required to reach maximum dimensions should be confirmed.

- More than one water-saturation/oven-dry cycle is required, especially when there is a chance of chemical leaching during the first water soak. Behaviour in the first cycle is generally not representative of behaviour in subsequent cycles. Three or more cycles are recommended, with results from the first cycle being discarded.

- If specimens are likely to crack during oven drying, a two-stage oven drying is recommended to reduce checking. For example, drying at $50{ }^{\circ} \mathrm{C}, 54 \% \mathrm{RH}$ followed by oven drying at $103{ }^{\circ} \mathrm{C}$ has been found to reduce cracking. If specimens do start to crack, it is recommended that they are not tested further.

\section{Swellometer tests}

Swellometer tests are also relatively quick to perform, but require a little more equipment than water-saturation tests. The swellometer test also shows how quickly the wood will take up water, which is important for situations, where the wood is only likely to be in contact with liquid water for short periods of time.
As with water-saturation tests, when preparing swellometer specimens, it is important to have consistent specimen dimensions, correct grain orientation and a smooth surface finish to give good results. Consistent radial and longitudinal dimensions are particularly important; this ensures that each specimen can move freely in the swellometer jig and does not become jammed.

\section{Humidity-cycling tests}

Humidity-cycling tests take much longer to complete than water-soaking tests, but in many end uses, wood will not routinely come in contact with liquid water, so a humidity-based test will be an important predictor of the wood behaviour in service. Common measures of dimensional stability from humidity-cycling tests can be used to compare different wood species, as well as comparing modified wood to its unmodified counterpart. Humidity-cycling tests may be better suited to more mature technologies, where understanding the in-service behaviour of the wood is important, and performance comparisons are being made with competing products, as well as unmodified controls.

The following are recommended (in approximate order of importance) for minimising experimental error in humidity tests:

- Do not oven-dry specimens prior to humiditycycling tests. Oven drying irreversibly alters the sorption behaviour of wood, and therefore, the behaviour measured is not representative of the original material. Oven drying should be performed after all humidity cycles are complete.

- Ensure sufficient time is given for specimens to reach equilibrium. Wood dimensions continue to change at a slower rate than the weight changes, and measuring specimens too early risks underestimating the degree of dimension change that would occur over long-time periods.

- Ensure growth rings are properly aligned with the measurement directions. Shrinkage is different in the radial and tangential directions, and misalignment between the growth rings and the measured direction will mean that the measured radial and tangential shrinkage will be different to the actual radial and tangential shrinkage.

- Do not water saturate specimens prior to humidity conditioning. Drying wood from above FSP leads to different dry dimensions to drying from below FSP. Saturating dry specimens with water prior to humidity cycling will alter the wood dimensions and not reflect the behaviour of the original wood. 
If water-saturation tests are to be performed on the same specimens as humidity-cycling testing, the humidity-cycling testing should be performed first.

- Perform at least 3 full humidity cycles, and discard the results from the first cycle. Behaviour in the first humidity cycle is often very different to subsequent cycles, so is not representative of the longterm wood behaviour.

- Prepare specimens with the largest practicable radial and tangential dimensions. These are the principle directions where shrinkage occurs, and therefore will reduce measurement errors, and ensure that small dimensional changes are larger than the measurement accuracy of the equipment used.

- Choose standard conditions to cycle between, e.g., $20{ }^{\circ} \mathrm{C}$ and 35,65 , and $90 \% \mathrm{RH}$. If $20{ }^{\circ} \mathrm{C}$ is problematic for low humidity conditions, $25^{\circ} \mathrm{C}$ can be used. It is important that all humidity conditions are at the same temperature, to eliminate thermal expansion effects. Using standard temperatures and humidities makes it easier to compare results from different studies.

- Use the most accurate and repeatable measurement technique available; a bench-mounted dial gauge is more accurate than hand-held calipers. In addition, computer-interfaced instruments reduce the risk of transcription errors, compared to recording values by hand.

- Mark dimensional measurement points with physical reference marks or tabs. This ensures that dimensions are consistently measured at the same point giving greater accuracy and repeatability.

- Pay attention to surface preparation-a smooth surface is required for accurate and repeatable dimension measurements.

- Minimise longitudinal direction dimension to ensure specimens equilibrate quickly. This reduces test durations, and minimises the likelihood of moisture gradients through the specimen, which may affect the specimen dimensions.

For short-term tests, in addition to the recommendations above:

- Ensure specimen dimensions (especially longitudinal) are the same for all specimens. This ensures a consistent ratio of surface area to wood volume for all specimens.

\section{Conclusions}

It is important that an appropriate stability test is chosen, and the test method used minimises experimental errors and ensures that representative results are obtained, given the importance of dimensional stability in predicting long-term behaviour of wood in service. Often, it is important to understand how wood behaves with changes in relative humidity as well as in contact with liquid water. Changes in atmospheric humidity will affect all end uses of wood, and even in situations, where contact with liquid water is unlikely (e.g., indoors) and it is still possible (e.g., spills and flooding).

Four types of test are outlined here, covering two types of moisture change (contact with liquid water, or humid air), and either long or short exposure periods. The choice of test type depends on the time that can be allocated to testing, and the types of moisture changes the wood would be expected to see in service.

For modified wood products, relatively fast tests are required early in the research process to screen different treatment methods. At this stage, performance comparisons are usually being made with unmodified control samples, so a fast comparative test such as the repeated water-soak test would be ideal.

As a modification method is developed further and comes closer to market, it is more appropriate to invest time in longer term tests such as humidity-cycling tests. This is especially appropriate if the wood is unlikely to come into contact with liquid water in service (e.g., for interior uses), or if performance comparisons need to be made between modified wood products and other competing products (e.g., other species of wood, or other building materials).

While there is currently little standardisation of dimensional stability test methods, there is a lot of evidence in the literature of test methods that will minimise experimental errors and give representative results. Guidelines are given in this paper for test methods that will reduce experimental errors and ensure that the behaviour being measured is representative of the wood being evaluated. Most of the guidelines do not require additional specialist equipment, and would be easy to implement.

As a further step towards developing standardised test methods, it is recommended that the guidelines outlined in this paper be used to create standardised dimensional stability test methods, and to assess the dimensional stability of a variety of wood types using these methods. 


\section{Abbreviations}

ASE: anti-shrink efficiency; ASE : anti-swell efficiency; EMC: equilibrium moisture content; FSP: fibre saturation point; $\mathrm{MC}$ : moisture content; $\mathrm{RH}$ : relative humidity; WRE: water-repellent efficiency; WRV: water-repellent percentage value.

\section{Acknowledgements}

Elizabeth Dunningham and Gavin Durbin provided suggestions on suitable test methods for accurate assessment of dimensional stability. Grant Emms, Lloyd Donaldson and Elspeth MacRae gave useful feedback on the structure and content of the manuscript.

\section{Authors' contributions}

RS: performed the literature review and wrote the manuscript. The author read and approved the final manuscript.

\section{Funding}

This study was funded by The New Zealand Ministry of Business, Innovation \& Employment through the Strategic Science Investment Fund.

\section{Availability of data and materials}

Data sharing is not applicable to this article, as no data sets were generated or analysed during the current study.

\section{Competing interests}

The author declares that she has no competing interests.

Received: 15 May 2019 Accepted: 18 July 2019

Published online: 25 July 2019

\section{References}

1. Van Acker J (2003) Assessing performance potential of modified wood focussing on dimensional stability and biological durability. Paper presented at the First European Conference on Wood Modification, 3-4 April 2003, Ghent, Belgium

2. Sargent R, Durbin GJ, Dunningham EA (2015) Measurement of dimensional stability. Paper presented at the 8th European Conference on Wood Modification, 24-25th October, Helsinki, Finland

3. Hill CAS (2006) Wood modification. Chemical, thermal and other processes. Wiley, Chichester

4. WDMA (2009) T.M. 2-1999 Test method to determine the short term anti-swell effectiveness of treating systems. The Window \& Door Manufacturers Association, Chicago, IL

5. Skaar C (1988) Wood-water relations. Springer series in wood science. Springer, Berlin

6. Noack D, Schwab E, Bartz A (1973) Characteristics for a judgment of the sorption and swelling behavior of wood. Wood Sci Technol 7:218-236

7. Bak M, Németh R (2012) Changes in swelling properties and moisture uptake rate of oil-heat-treated poplar (Populus $\times$ euramericana cv. pannónia) wood. BioResources 7:5128-5137

8. Hill CAS, Farahani MRM, Hale MDC (2004) The use of organo alkoxysilane coupling agents for wood preservation. Holzforschung 58:316-325

9. Vukusic SB, Katovic D, Grgac SF, Trajkovic J, Sefc B, Voncina B (2010) Study of the wood modification process with polycarboxylic acids and microwave tratment. Wood Res-Slovakia 55:121-130

10. Hill C, Jones D (1996) The dimensional stabilisation of corsican pine sapwood by reaction with carboxylic acid anhydrides. Holzforschung 50:457-462

11. Šefc B, Trajkovic J, Hasan M, Katovic D, Vukusic SB, Martina F (2009) Dimensional stability of wood modified by citric acid using different catalysts/Stabilnost dimenzija drva modificiranoga limunskom kiselinom uz razlicite katalizatore. Drvna Ind 60:23

12. Gündüz G, Korkut S, Korkut DS (2008) The effects of heat treatment on physical and technological properties and surface roughness of Camiyani Black Pine (Pinus nigra Arn. subsp. pallasiana var. pallasiana) wood. Bioresource Technol 99:2275-2280

13. Dubey MK, Pang S, Walker J (2012) Changes in chemistry, color, dimensional stability and fungal resistance of Pinus radiata $D$. Don wood oil heat-treatment. Holzforschung 66:49-57
14. Fredriksson M, Wadsö L, Ulvcrona T (2010) Moisture sorption and swelling of Norway spruce [Picea abies (L.) Karst.] impregnated with linseed oil. Wood Mat Sci Eng 5:135-142

15. Ohmae K, Minato K, Norimoto M (2002) The analysis of dimensional changes due to chemical treatments and water soaking for hinoki (Chamaecyparis obtusa) wood. Holzforschung 56:98-102

16. García Esteban L, Gril J, Palacios De Palacios De, Guindeo Casasús A (2005) Reduction of wood hygroscopicity and associated dimensional response by repeated humidity cycles. Ann For Sci 62:275-284. https:// doi.org/10.1051/forest:2005020

17. Almeida G, Hernández RE (2007) Dimensional changes of beech wood resulting from three different re-wetting treatments. Holz Roh Werkst 65:193-196

18. Naderi N, Hernández RE (1997) Effect of re-wetting treatment on the dimensional changes of sugar maple wood. Wood Fiber Sci 29:340-344

19. Rowell R (1983) Chemical modification of wood. For Prod Abstr 6:363-382

20. Čermák P, Rautkari L, Horáček P, Saake B, Rademacher P, Sablík P (2015) Analysis of dimensional stability of thermally modified wood affected by re-wetting cycles. BioResources 10:3242-3253. https://doi.org/10.15376/ biores.10.2.3242-3253

21. Chafe SC (1995) Preheating and continous and intermittent drying in boards of Eucalyptus-regnans f muell. 1. Effect on internal checking, shrinkage and collapse. Holzforschung 49:227-233. https://doi. org/10.1515/hfsg.1995.49.3.227

22. DIN 52184 (1979) Testing of wood; determination of swelling and shrinkage

23. ASTM D2395 (2014) Standard test methods for density and specific gravity (relative density) of wood and wood-based materials

24. Schmidt EL, Murphy TP, Cheeks CN, Ross AS, Chiu TS, Williams RS (2002) Comparisons of interlaboratory swellometer testing of two water-repellent preservative formulations for millwork. For Prod J 52:82-84

25. Khalil HPSA, Amouzgar P, Jawaid M, Abdullah CK, Issam AM, Zainudin ES, Paridah MT, Hassan A (2013) Physical and thermal properties of microwave-dried wood lumber impregnated with phenol formaldehyde resin. J Compos Mater 47:3565-3571. https://doi.org/10.1177/00219 98312467386

26. ASTM D4446 M (2013) Anti-swelling effectiveness of water-repellent formulations and differential swelling of untreated wood when exposed to liquid water environments

27. Anonymous (2010) Wood Handbook - wood as and engineering material. General technical report FPL-GTR-190. U.S. Department of Agriculture, Forest Service, Forest Products Laboratory, Madison, WI

28. ISO 4469 (1981) Wood-determination of radial and tangential shrinkage

29. Bekhta P, Niemz P (2003) Effect of high temperature on the change in color, dimensional stability and mechanical properties of spruce wood. Holzforschung 57:539-546

30. Mazzanti P, Togni M, Uzielli L (2012) Drying shrinkage and mechanical properties of poplar wood (Populus alba L.) across the grain. J Cult Herit 13:S85-\$89

31. Lande S, Westin M, Schneider M (2004) Properties of furfurylated wood. Scand J For Res 19(Supplement 5):22-30

32. Esteves BM, Pereira HM (2009) Wood modification by heat treatment: a review. BioResources 4:370-404

33. Awoyemi $L$ (2004) Effects of microwave modification on the shrinkage properties of Eucalyptus obliqua wood. J I Wood Sci 16:199-203

34. Sik HS, Choo KT, Zakaria S, Ahmad S, How SS, Chia CH, Yusoff M (2010) Dimensional stability of high temperature-dried rubberwood solid lumber at two equilibrium moisture content conditions. Dry Technol 28:1083-1090

35. Rautkari L, Hill CAS (2014) Effect of initial moisture content on the antiswelling efficiency of thermally modified Scots pine sapwood treated in a high-pressure reactor under saturated steam. Holzforschung 68:323-326

36. Hoffmeyer P, Engelund ET, Thygesen LG (2011) Equilibrium moisture content (EMC) in Norway spruce during the first and second desorptions. Holzforschung 65:875-882

37. Weise U, Paulapuro H (1998) Relation between fiber shrinkage and hornification. Prog Pap Recycl 7:14-21

38. Östlund $\AA$, Köhnke T, Nordstierna L, Nydén M (2010) NMR cryoporometry to study the fiber wall structure and the effect of drying. Cellulose $17: 321-328$ 
39. Pönni R, Vuorinen T, Kontturi E (2012) Proposed nano-scale coalescence of cellulose in chemical pulp fibers during technical treatments. BioResources 7:6077-6108

40. Hill CAS, Ramsay J, Laine K, Rautkari L, Hughes M (2013) Water vapour sorption behaviour of thermally modified wood. Int Wood Prod $J$ 4:191-196

41. Rowell RM, Wang RHS, Hyatt JA (1986) Flakeboards made from aspen and southern pine wood flakes reacted with gaseous ketene. J Wood Chem and Technol 6:449-471

42. Edvardsen K, Sandland KM (1999) Increased drying temperatureits influence on the dimensional stability of wood. Holz Roh Werk 57:207-209

43. Ding T, Gu L, Li T (2011) Influence of steam pressure on physical and mechanical properties of heat-treated Mongolian pine lumber. Eur J Wood Wood Prod 69:121-126

44. Ishimaru Y, Arai K, Mizutani M, Oshima K, lida I (2001) Physical and mechanical properties of wood after moisture conditioning. J W Sci 47:185-191

45. Rafidah KS, Hill CAS, Ormondroyd GA (2006) Dimensional stabilization of rubberwood (Hevea brasiliensis) with acetic or hexanoic anhydride. J Trop For Sci 18:261-268

46. BS/EN 318 (2002) Wood based panels. Determination of changes associated with changes in relative humidity
47. AS/NZS 4266.14 (2004) Reconstituted wood-based panels — methods of test

48. Barkas WW (1949) The swelling of wood under stress. Forest Products Research Laboratory; Department of Scientific and Industrial Research, London

49. Pfriem A, Grothe T, Wagenführ A (2007) Influence of thermal modification on the unsteady sorption behavior of Norway spruce (Picea abies (L.) Karst.). Holz Roh Werkst 65:321-323

50. Harris JM (1961) The dimensional stability shrinkage intersection point and related properties of new zealand timbers. Forest Research Institute, New Zealand Forest Service

51. Haslett AN (1986) Properties and utilisation of exotic specialty timbers grown in New Zealand

\section{Publisher's Note}

Springer Nature remains neutral with regard to jurisdictional claims in published maps and institutional affiliations.

\section{Submit your manuscript to a SpringerOpen ${ }^{\circ}$ journal and benefit from:}

- Convenient online submission

- Rigorous peer review

- Open access: articles freely available online

- High visibility within the field

- Retaining the copyright to your article

Submit your next manuscript at $\boldsymbol{\sim}$ springeropen.com 